\title{
El poblamiento ibérico en el Noroeste Murciano: una aproximación al oppidum de Los Villaricos a través de su patrón de asentamiento.
}

\author{
Leticia López-Mondéjar \\ Universidad de Murcia
}

\section{Resumen}

El presente trabajo pretende llevar a cabo una primera aproximación al importante oppidum de Los Villaricos (Caravaca de la Cruz, Murcia), a través del análisis de la estrategia locacional de dicho centro y de las posibilidades que ofrece un estudio de conjunto del paisaje ibérico en estos territorios del Sureste peninsular. Se intenta abordar así el papel que pudo desempeñar este asentamiento en el Noroeste murciano, prestando especial atención a los criterios que definen la organización territorial ibérica en este sector regional.

PALABRAS CLAVE: época ibérica, patrón de asentamiento, organización territorial, Murcia, Los Villaricos, Cerro de la Ermita de La Encarnación.

\section{Riassunto}

Il presente lavoro si presenta come un approccio iniziale all'importante oppidum di Los Villaricos (Caravaca de la Cruz, Murcia), partendo dall'analisi del suo modelo insediativo e delle posibilità che offre uno studio di insieme del paessagio iberico di questi territori del Sud-est della Penisola Iberica. Si affronta così il ruolo di questo sito nel popolamento del Nord-ovest murciano, e si approfondisce inoltre i criteri che definiscono la organizzazione territoriale iberica in quest'area regionale.

PAROLE CHIAVE: età iberica, modello di insediamento, organizzazione territoriale, Murcia, Los Villaricos, Cerro de la Ermita de La Encarnación.

\section{INTRODUCCIÓN.}

El oppidum ibérico de Los Villaricos es uno de los yacimientos más destacados de la comarca murciana del Noroeste y del Sureste peninsular. A pesar de ello, sin embargo, y aunque las noticias sobre los restos arqueológicos de este sector regional murciano se remontan a época moderna, resulta también uno de los núcleos ibéricos más desconocidos de la actual Región de Murcia, quedando tradicionalmente, y aun hoy en día, a la sombra de importantes y célebres conjuntos ibéricos como los localizados en El Cigarralejo (Mula) o Coimbra del Barranco Ancho (Jumilla).

La ausencia de excavaciones en el yacimiento y la escasa información aportada por los datos obtenidos en los trabajos de urgencia realizados en su necrópolis, han contribuido, en gran medida, a dicho desconocimiento, centrándose la atención, en cambio, en el vecino Cerro de la Ermita de La Encarnación. Este santuario ibérico experimentará, durante los siglos previos al 
cambio de Era, una importante transformación edilicia, convirtiéndose en uno de los yacimientos clave para comprender el desarrollo del proceso de romanización en toda este área del Sureste peninsular.

Los últimos estudios que, en el marco de la arqueología del paisaje se están desarrollando en otros ámbitos ibéricos de la Península, han puesto de manifiesto la amplia información que, junto a los datos propiamente arqueológicos, procedentes, sobre todo, de los trabajos de excavación, puede aportar el análisis de la decisión locacional que define a los núcleos de este periodo y, especialmente, a aquellos centros que, como Los Villaricos, debieron jugar un papel clave en la configuración del paisaje y en la articulación del poblamiento. Sólo en el marco de dicho paisaje ibérico, y del papel que este centro desempeñaría durante el Ibérico Pleno en la comarca del Noroeste murciano, podremos comprender el modelo de control y organización territorial de esta zona, así como los cambios que experimentará el vecino santuario de La Encarnación ante la presencia romana.

Desde esta perspectiva, y teniendo especialmente presente la ausencia de datos arqueológicos más concretos sobre este oppidum murciano, creemos que puede ser interesante llevar a cabo una primera aproximación al patrón de asentamiento de este centro que nos permita ir más allá, ayudándonos a comprender su papel en el conjunto del poblamiento ibérico comarcal. Si bien se trata de una cuestión no abordada hasta ahora en ninguno de los estudios que han afrontado el análisis del mundo ibérico en este área regional, puede constituir, sin embargo, y gracias a las nuevas posibilidades que ofrecen las metodologías SIG, un excelente punto de partida para aproximarnos a uno de los núcleos ibéricos más destacados de todo el Sureste peninsular.

Partiendo de ese objetivo principal, atenderemos a los criterios que pueden ofrecernos una imagen más precisa de la decisión locacional de este asentamiento. Analizaremos asi aquellos rasgos que definen su emplazamiento, su carácter estratégico y el control que pudo ejercer sobre los territorios, recursos naturales y ejes viarios de su entorno para comprender dicho asentamiento en el conjunto del paisaje que, desde el siglo IV a.C. se configura en el valle del Quípar.

\section{EL OPPIDUM DE LOS VILLARI- COS Y SU LOCALIZACIÓN EN EL TERRITORIO COMARCAL: ASPEC- TOS DEFENSIVOS Y ESTRATÉ- GICOS DE SU PATRÓN DE ASENTA- MIENTO.}

La comarca del Noroeste, en la que se sitúa el núcleo ibérico de Los Villaricos, se ubica en el sector interior de la actual Región de Murcia, al abrigo de las Béticas, drenada por los ríos Argos y Quípar, afluentes del Segura por su margen derecha. A pesar de ser una de las áreas murcianas más alejadas del litoral, este hecho no ha impedido, durante siglos, la comunicación constante entre estas tierras interiores y dicho ámbito costero, constituyendo los citados cursos fluviales y la propia disposición de los relieves que dominan y rodean la comarca, claras vías de enlace entre el sector litoral y el mundo andaluz granadino.

Si bien la comarca ofrece claros rasgos en común con el resto del territorio de la actual Región de Murcia, presenta también un carácter propio, sobre todo si atendemos a sus condiciones climáticas y geomorfológicas, que la han dotado tradicional e históricamente de una originalidad que la diferencia ampliamente de las comarcas vecinas.

Dentro de ella, es quizás el área del Estrecho de las Cuevas, también conocida como Estrecho de La Encarnación, uno de los sectores clave dentro de la comarca, sobre todo si atendemos a los ejes que marcarían la circulación por estas tierras, configurándose como un punto de paso natural y obligado en el acceso al valle del Segura. Es precisamente aquí donde se ubica el que debió constituirse como uno de los principales centros ibéricos de la zona, el oppidum de Los Villaricos, sin olvidar, también, la localización del citado complejo arqueológico de $\mathrm{La}$ Encarnación. Dichos yacimientos no hacen sino presentar este sector del Noroeste murciano como un área fundamental para comprender la dinámica histórica y los rasgos que definen el paisaje ibérico e ibero-romano en estos territorios del interior regional (figura 1)

Es este emplazamiento, en un punto de especial interés dentro de la comarca, el que tal vez defina mejor al citado oppidum, ofreciéndonos una primera aproximación al mismo. Su patrón de asentamiento, si bien estará ampliamente con- 


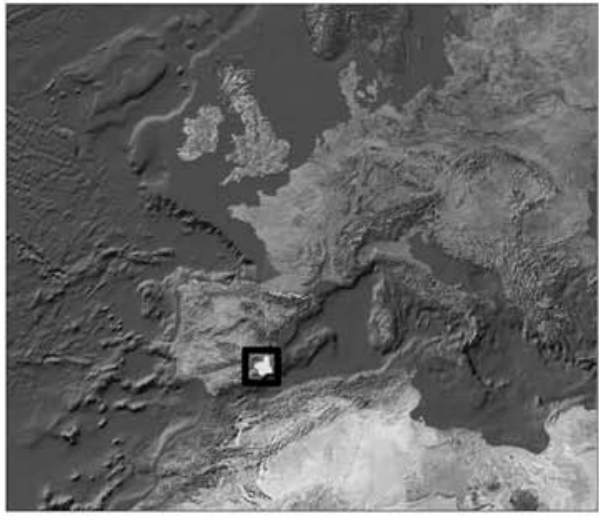

\section{Comarca del Noroeste murciano y localización del área de estudio}
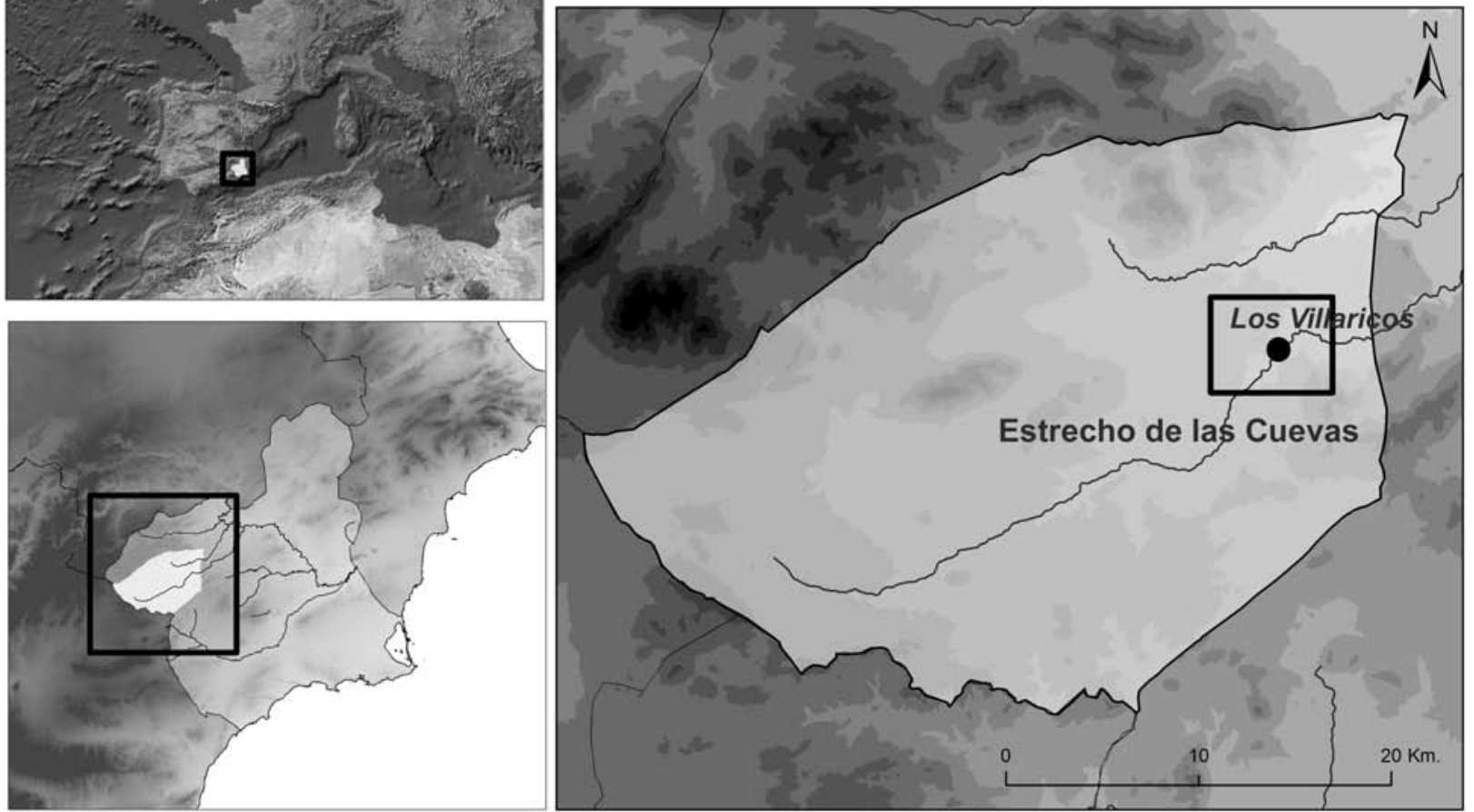

Figura 1. Localización del Estrecho de La Encarnación y emplazamiento del oppidum ibérico de Los Villaricos.

dicionado por los propios rasgos orográficos de este área murciana y por los recursos que caracterizarán su entorno más inmediato, enlaza con aquel que caracterizaría a la mayor parte de los grandes centros ibéricos del Sureste peninsular y, concretamente, del ámbito murciano, como el vecino asentamiento de Los Villares.

El oppidum de Los Villaricos aparece así situado en uno de los cerros que se elevan en las inmediaciones del curso del Quípar, en el mencionado Estrecho de las Cuevas, a unos 790 metros de altitud sobre el nivel del mar y a una cota muy superior a la de las tierras circundantes. A pesar de esa posición, claramente visible y destacada en el entorno, el asentamiento se emplaza en una amplia plataforma amesetada, de unas 7 hectáreas, que permitiría el desarrollo de un hábitat de considerable extensión durante el periodo ibérico (Brotóns Yagüe, 1995: 251, nota 11). Desgraciadamente, el escaso conocimiento que aun tenemos de este centro, y la ausencia de trabajos de excavación en el mismo, no nos permiten aproximarnos a la posible organización interna del espacio habitado, si bien, en superficie, parecen advertirse estructuras de vivienda
(Melgares, 1974; Ramallo Asensio y Ros Sala, 1993).

Por lo que respecta a la necrópolis y al santuario que quedarían asociados a este destacado núcleo ibérico, aparecen situados en sus proximidades. La primera se localiza a una cota inferior, a unos cientos de metros al suroeste del poblado y controlada visualmente desde éste. El santuario, por su parte, se ubica en la margen derecha del río Quípar, en el mencionado Cerro de la Ermita de La Encarnación, en un área de carácter forestal, como suele ser común a este tipo de emplazamientos, donde la vegetación pudo suponer un obstáculo visual para la conexión entre este área y el oppidum (Prados Torreira, 1994: 135-137).

Volviendo a Los Villaricos, llama ampliamente la atención, en el marco del paisaje comarcal, el emplazamiento elegido por este núcleo. Ubicado junto al río Quípar, el cerro sobre el que se instala el poblado, aparece rodeado de destacados sectores de pendiente, presentando un fuerte cortado en su vertiente más oriental, por donde discurre el mencionado curso 
fluvial formando un estrecho desfiladero entre cantiles, así como también en sus vertientes norte y noreste, donde encontramos el Barranco de Cavila. El acceso al oppidum se presenta así impracticable por los sectores señalados, siendo únicamente la ladera más occidental, en la que, además situó ya Marín de Espinosa la posible entrada al espacio de hábitat, la que ofrece una mayor facilidad de acceso (Marín De Espinosa, 1856 (reed. 1975): 12-13; Melgares, 1974; Ramallo Asensio y Ros Sala, 1993: 69-70).

A pesar de ello, esas dificultades de acceso, así como la elevada cota a la que este centro se sitúa en relación a las tierras de su entorno, le confieren, sin embargo, otras ventajas: unas óptimas posibilidades defensivas y un amplio dominio visual de las tierras, recursos, ejes viarios y asentamientos de su entorno.

Por lo que respecta a esta última cuestión, y si atendemos a la amplia cuenca visual de este centro, se advierte claramente que debió ejercer un claro control visual de gran parte de las tierras aptas para las actividades agrícolas que se extienden en este sector comarcal (figura 2). No podemos olvidar además, en este sentido, que este área, en la que los cursos fluviales del Argos y del Quípar se localizan más próximos y en la que encontramos múltiples manantiales que favorecen el regadío, es precisamente una de las que ofrecen mayores posibilidades de explotación agropecuaria de todo el ámbito comarcal, siendo en ella en la que se han concentrado tradicionalmente este tipo de actividades (Alías, 1991; Madoz, 1850 (reed. 1989)).

Junto a ese amplio y rico sector de altiplanos, el núcleo emplazado en Los Villaricos lograría, además, un importante control visual de la ruta de comunicación natural que siguiendo el cauce de los citados cursos fluviales y atravesando las fértiles altiplanicies señaladas, alcanzaría las tierras andaluzas, enlazando de este modo el ámbito granadino con el valle del Segura y con el propio litoral levantino.

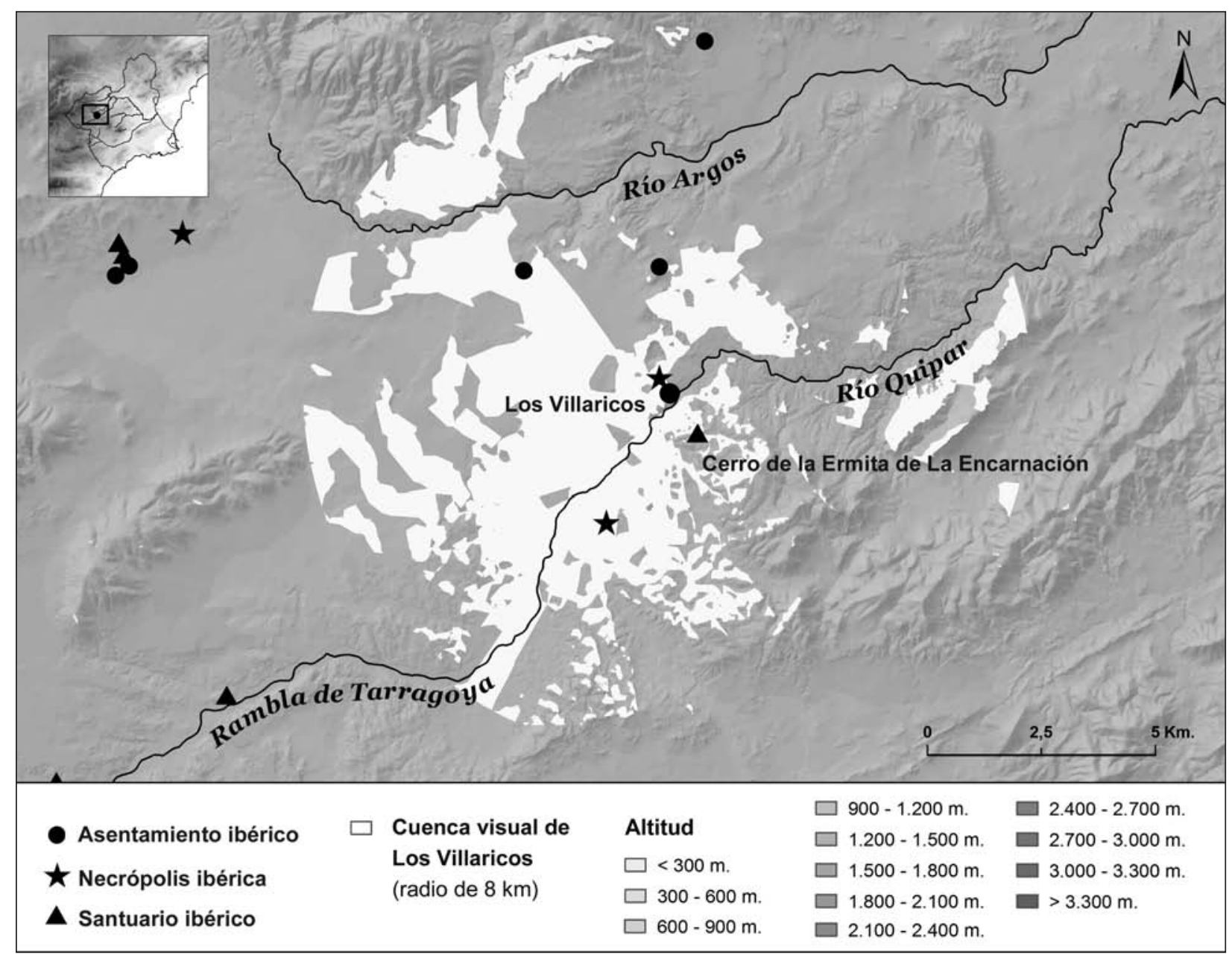

Figura 2. Cuenca visual del oppidum de Los Villaricos. 
La visibilidad de este centro quedará así únicamente limitada en dirección norte y noreste, debido sobre todo a las alturas que presentan las sierras de Las Cabras y de Burete, y al más que probable predominio de los espacios forestales que, como veremos, pudo caracterizar toda este área situada en la margen derecha del Quípar (Rivera, Obón y Asencio, 1988: 321-325; Alías Pérez, 1991).

Desde este punto de vista, el emplazamiento parece responder a unos intereses concretos $y$, en este sentido, debemos suponer que existirían determinados sectores cuyo control debió ser primordial para el citado oppidum. Si atendemos a su cuenca visual ésta comprende, en un radio de 8 kilómetros, todo el valle medio-alto del Quípar, el sector situado al suroeste del yacimiento y la rambla de Tarragoya. En este último, como hemos indicado, se concentran las tierras más aptas para la explotación agrícola y por él discurre la ruta natural de comunicación entre el área de Cehegín y los territorios granadinos, siguiendo probablemente un trazado similar al que hoy en día muestra la carretera que alcanza, desde Caravaca de la Cruz, el entorno de la población de Barranda. Junto a esa ruta principal, desde el oppidum se tendría también un importante control visual de las numerosas rutas ganaderas que discurren por la comarca del Noroeste murciano, entre ellas las que atraviesan todo este sector de altiplanos de Singla y Pinilla, y las que se dirigen a Archivel y hacia tierras lorquinas, atravesando el área de Campo Coy (figura 3).

En cuanto al segundo de los aspectos apuntados, referido a las condiciones defensivas que caracterizan el patrón de asentamiento de este centro, su estrategia locacional le proporcionaría, como hemos señalado, una excelente protección natural gracias a las fuertes pendientes de su entorno. Ésta queda completada, además, con la construcción de una amplia muralla, de más

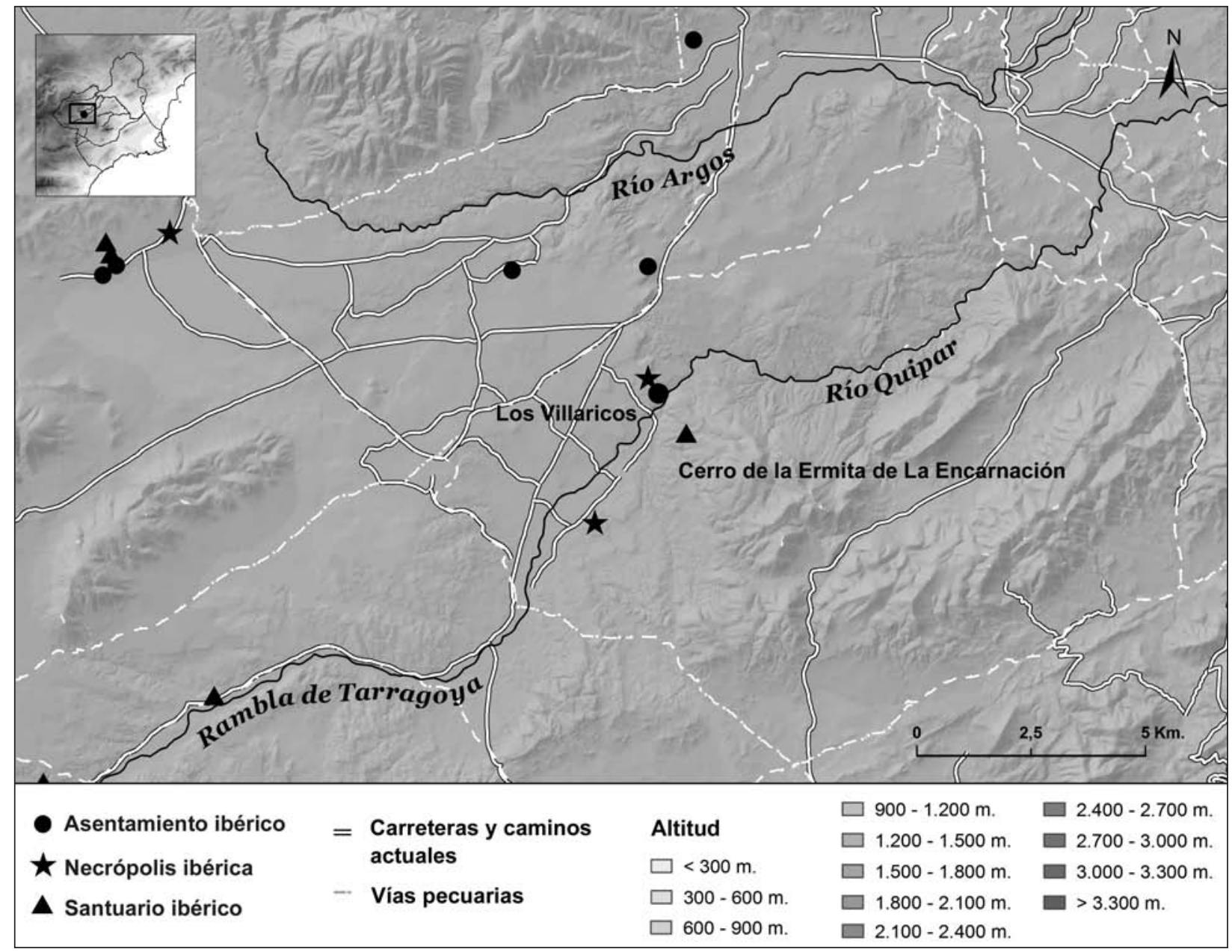

Figura 3. Rutas de comunicación y vías pecuarias que discurren en las proximidades del Estrecho de las Cuevas y del oppidum de Los Villaricos. 
de 350 metros de longitud, formada por un doble paramento de piedras irregulares, relleno de tierra y de otras de menor tamaño. Si atendemos a la tipología definida por P. A. Lillo, el oppidum que nos ocupa se engloba entre aquellos centros ibéricos regionales que completan sus condiciones defensivas con la construcción de un 'cinturón’ en los sectores de más fácil acceso (Melgares, 1974: 174-181; Lillo, 1981: 15-17; Ramallo y Ros, 1993). Este tipo de fortificaciones disminuyen además en calidad, según P. A. Lillo, a partir de mediados del siglo IV a.C., siendo de mayor envergadura durante la fase más antigua del mundo ibérico regional. En este sentido, quizás sea uno de los más representativos el caso de Los Villaricos y del vecino oppidum de Los Villares. Éste, situado al otro lado del curso del Quípar, presenta en superficie una imponente muralla, completada con torres cuadradas distribuidas a lo largo de la misma (Ramallo y Ros, 1993: 69-70; García e Iniesta, 1984: 72-74).

En general, serán fundamentalmente los grandes núcleos de población los que ofrecerán este tipo de estructuras defensivas, tal y como se observa en la propia comarca del Noroeste regional, donde únicamente centros como el que ahora nos ocupa o el vecino oppidum de Los Villares aparecen caracterizados por esas murallas. Junto a ellos, sin embargo, no podemos olvidar la presencia de ciertas excepciones, como el poblado de Los Molinicos, en Moratalla, cuyas estructuras defensivas ofrecen claros paralelos con las del área andaluza turdetana y cuya cronología, carácter y entidad parecen alejarlo de los rasgos que definen al núcleo instalado en Los Villaricos (Lillo, 1993: 27-50).

Dejando a un lado el caso de Los Molinicos, el carácter funcional de este tipo de estructuras es también claro en la mayor parte de los oppida murcianos, en los que parecen adaptarse a la propia topografía natural del terreno, localizándose en aquellas áreas más desprotegidas del yacimiento. A pesar de ello, y aunque se ha valorado especialmente ese carácter práctico que, por otro lado, es más que claro en todos los casos, no podemos descartar el papel simbólico que dichas fortificaciones pudieron desempeñar en el marco espacial en el que se establecen estos centros (Lillo, 1981: 11-14 y 1985: 277; Grau, 2004: 6872; Moret, 2003: 177-180). Dicho papel, tendría también probablemente un cierto protagonismo en el caso de Los Villaricos, especialmente si atendemos a la entidad de este centro y al hecho de que sea el único núcleo comarcal, dejando a un lado el vecino oppidum de Los Villares, que ofrece este tipo de defensas.

En este sentido, el propio panorama que ofrece el poblamiento ibérico en este ámbito regional pone de manifiesto la importancia del oppidum de Los Villaricos en el valle. El carácter secundario de esos otros centros, carentes de defensas, y su escasa entidad frente al citado oppidum, apunta a este núcleo como aquel que se situaría a la cabeza del territorio y de esos establecimientos rurales, cuyo patrón de asentamiento, refleja su interés por la explotación agropecuaria del entorno y unas escasas posibilidades defensivas que, en la mayor parte de los casos. De este modo, y si atendemos a los rasgos apuntados en relación a su estrategia locacional, el oppidum de Los Villaricos debió funcionar así, frente a estos centros, como el núcleo principal, articulador y organizador de todo el poblamiento de este área interior murciana.

Partiendo de su destacada posición en el conjunto del poblamiento ibérico de los valles del Argos y el Quípar durante los siglos IV-III a.C., y también en conexión con esas defensas artificiales, no podemos descartar el interés de este asentamiento en 'ser visto', constituyendose como punto de referencia en el paisaje comarcal (Criado, 1999: 18-19; Grau, 2004: 68-72; Mañana, Blanco y Ayán, 2002: 38-39). En este sentido, sus murallas vuelven a ofrecer un carácter simbólico junto al meramente funcional, confirmándose además ese interés por la elección de un emplazamiento, como el indicado, predominante en el paisaje. A ello debemos añadir la propia continuidad de Los Villaricos tras la llegada romana al Sureste peninsular, aspecto que también puede interpretarse en esta misma línea.

No podemos olvidar el interés de Roma por mantener el status quo en estos primeros momentos de su presencia en la Península Ibérica. Así favorecerá la continuidad, como se ha apuntado para otras áreas ibéricas peninsulares, de aquellos centros que pudieron funcionaron desde el periodo anterior como núcleos organizadores a nivel territorial, y en los que residió la elite indígena que se hallaba a la cabeza de estos territorios. Este hecho es también una de las claves que quizas expliquen la pervivencia de este oppidum hasta época imperial, así como la transformación edilicia que experimentará el santuario ibérico vincu- 
lado a él, en el vecino Cerro de la Ermita de La Encarnación. Si a todo ello sumamos, además, la localización de Los Villaricos junto a uno de los principales ejes naturales de comunicación de la comarca, tal y como demuestran la dispersión de las importaciones áticas e itálicas y la propia distribución del poblamiento a lo largo de la misma (Brotóns, 1995: 252-253; Brotóns y Murcia, 2008; Adroher y López, 2004: 97-110; Quesada, 1992: 66 у 2001-2002: 17-18; Quesada y Martínez, 1995: 248-249), debemos apuntar al claro interés de este centro por mostrarse como núcleo de referencia de toda este área. No olvidemos, en este sentido, que será precisamente en las proximidades de esa ruta natural de enlace entre las tierras andaluzas y el valle del Segura, donde se situará la mayor parte de los centros ibéricos e ibero-romanos documentados en este área regional, hecho que favorecerá, al mismo tiempo, la conexión visual entre el oppidum y esos establecimientos de segundo orden dispersos por el valle.

En cualquier caso, y al margen del posible valor simbólico de las murallas de este centro, parece claro que la presencia romana en la comarca pone de manifiesto el carácter estratégico de dicho núcleo. Si bien la mayor parte de los establecimientos que aparecen dispersos en los valles del Argos y el Quípar a lo largo de los siglos IVIII a.C., parece abandonarse en estos momentos, el oppidum de Los Villaricos muestra una clara continuidad. A diferencia de otras áreas del Sureste donde el siglo II a.C. supondrá la desaparición y el declive paulatino de muchos de los grandes centros ibéricos del periodo anterior, en el Noroeste regional vemos una permanencia de este centro que además pudo incluso desarrollar, tal y como se ha planteado, un posible papel estratégico durante los conflictos desarrollados en la zona entre partidarios de César y Pompeyo (Brotóns y Murcia, 2008: 50-64). En este sentido, no podemos olvidar los dos castella localizados en la comarca, en las proximidades de las actuales poblaciones de Barranda y Archivel (Brotóns y Murcia, 2008: 50-64), destinados a lograr el control de la vía de acceso a Andalucía a través de estas tierras. Ambos pondrían de manifiesto la continuidad de dicha ruta al menos hasta el siglo I a.C., ofreciendo, además, una clara conexión visual con el oppidum.

Finalmente, la citada transformación edilicia durante el periodo ibero-romano del santuario vinculado al mismo, presenta también a Los Villaricos como un centro fundamental para com- prender la integración de este área en la órbita de Roma. Todo ello confirma el carácter estratégico del asentamiento tanto en época ibérica como durante esas centurias previas al cambio de Era.

En definitiva, la búsqueda de un emplazamiento próximo a las rutas de comunicación e intercambio constituye, junto a ese interés defensivo y por lograr una posición destacada en el territorio, un criterio fundamental para comprender la decisión locacional de este asentamiento, al igual que ocurre con algunos de los grandes núcleos ibéricos del Sureste peninsular, como el propio Tolmo de Minateda y el oppidum de Piedra de Peñarrubia, que ejercería un destacado control en el acceso al área de Castulo (Sanz Gamo, 1999: 281-284).

\section{CRITERIOS ECONÓMICOS EN LA DECISIÓN LOCACIONAL DEL OPPIDUM DE LOS VILLARICOS.}

Sin olvidar los criterios apuntados y el papel que aspectos como los defensivos y estratégicos pudieron jugar en la elección de este emplazamiento, debemos plantear también, para lograr una visión más completa de su patrón de asentamiento, la importancia que otros factores desempeñaron, como aquellos de tipo económico.

Si bien es cierto que no podemos dar un valor principal a los aspectos económicos ni hacerlos extensivos a la totalidad de los asentamientos (Hodder y Orton, 1999: 251-253 y 256-258), lo cierto es que, como se ha apuntado, ni los individuos ni las culturas parecen interesarse por lo general por territorios incapaces de satisfacer sus necesidades primarias y garantizar, en cierto modo, la supervivencia de la comunidad. Esto significa, para el ser humano, disponibilidad de agua, tierras, etc. (Macchi, 2001: 9).

La mayor parte de los estudios que han abordado el análisis de los paisajes ibéricos y los rasgos que definen el patrón de asentamiento de los principales centros conocidos durante este periodo en el levante y sur peninsular apuntan al interés de estos núcleos por localizarse en áreas que no sólo les permitirían una posición estratégica, sino también, una amplia explotación de las tierras y recursos del entorno capaz de mantener a una población más o menos numerosa.

El escaso poblamiento documentado en las proximidades de Los Villaricos, como parece advertirse también en el entorno de otros núcleos 
del Sureste, como el Cerro del Castillo de Lorca, y la aparente ausencia de posibles establecimientos rurales de carácter secundario que pudiesen funcionar como centros destinados a la explotación de estos territorios, debe probablemente implicar una explotación directa de esas tierras más próximas al oppidum por sus habitantes (Ruiz, 1987, 9-20). Desde este punto de vista el acceso a los posibles recursos naturales de su entorno constituye, junto a los criterios señalados, un factor más que nos aproximaría al patrón de asentamiento de este núcleo y, en general, a los rasgos que pudieron definir el modelo de explotación económica en este sector del Noroeste murciano.

Las fuertes pendientes que caracterizan, como hemos apuntado, el entorno más inmediato del asentamiento de Los Villaricos, y especialmente su sector más oriental, condicionan en gran medida el acceso que los habitantes del mismo debieron tener a las tierras y recursos que se localizan en las inmediaciones del oppidum. El área de captación teórica del asentamiento quedaría así redu- cida, debido a la orografía que define el entorno del yacimiento. En el intervalo de una hora de camino, alcanzaría una distancia máxima de poco más de 4 kilómetros, frente a los teóricos 5 kilómetros que corresponderían a un terreno llano y sin dificultades para el tránsito. Este intervalo será todavía menor, e inferior incluso a los 3 kilómetros, en dirección noreste y sureste, donde se localizan aquellos sectores con pendientes más destacadas. El área total que quedaría encuadrada en esa isocrona de una hora de camino en torno al yacimiento, ofrece una extensión amplia, llegando a superar las 2800 hectáreas (figura 4).

La mayor parte de los grandes núcleos ocupados durante el Ibérico Pleno y localizados en el territorio murciano se caracterizan por presentar áreas de captación teóricas que abarcan, en general, y a pesar en muchos casos de sus posiciones estratégicas e inaccesibles, amplias zonas de su entorno. Aun así, dichas extensiones varían ampliamente en función de las propias características orográficas del sector regional en el que se emplazan, tal y como se observa también,

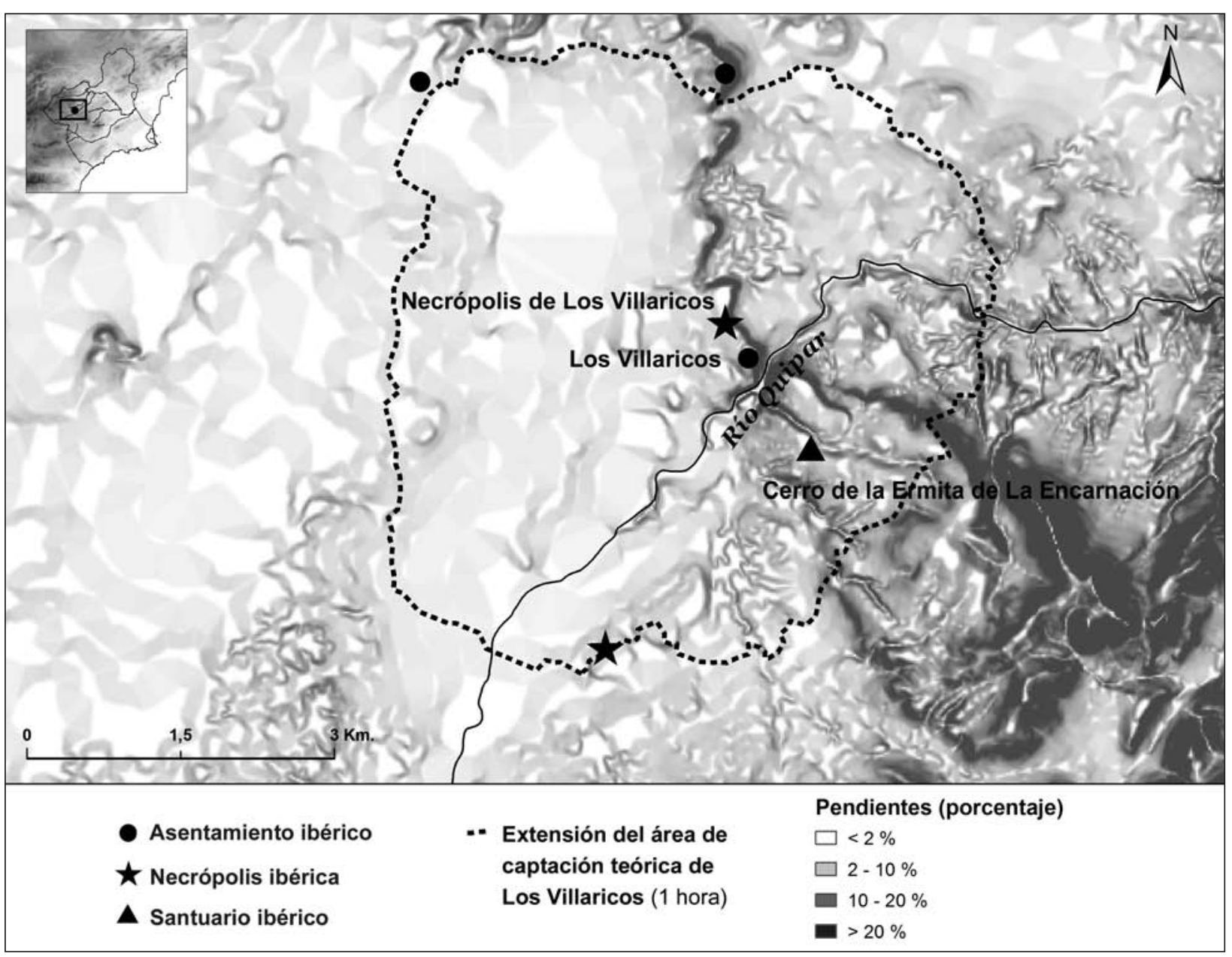

Figura 4. Mapa de pendientes en el entorno del Los Villaricos y extensión del área de captación económica del yacimiento. 
entre los vecinos centros ibéricos alicantinos de este mismo periodo. En este sentido, los estudios desarrollados en los valles de L'Alcoià y El Comtat muestran, para el Ibérico Pleno, territorios de explotación con extensiones que se sitúan entre las 2000 y las 400 hectáreas, advirtiéndose así la presencia de centros con amplias áreas de captación como es el caso de La Ermita de Planes, el Puig y el Castellar, frente a otros situados muy por debajo de esas cifras (Grau, 2002: 145-160).

Volviendo al área murciana, dichas superficies oscilan entre las casi 3000 hectáreas del Cabezo del Tío Pío, en Archena, y las aproximadamente 1300 de Coimbra del Barranco Ancho de Jumilla, situándose a la cabeza núcleos como El Cigarralejo de Mula, Bolbax en Cieza, Las Cabezuelas de Totana y el Cerro del Castillo de Lorca, con una extensión de más de 2500 hectáreas. Tan sólo poblados y establecimientos de entidad secundaria, como algunos de los localizados en el propio Noroeste murciano, o el centro ubicado en Los Molinicos, cuyo desarrollo además cabría situar en un momento anterior a mediados del siglo IV a.C., ofrecen un área de captación más amplia, claramente en conexión con su carácter agropecuario y, en ocasiones, con su posición alejada de las principales rutas y ejes viarios de este periodo (Lillo, 1993).

De este modo, podríamos decir que el núcleo de Los Villaricos se encontraría entre aquellos oppida ibéricos del Sureste peninsular que presentarían un acceso más amplio a las tierras y recursos agropecuarios del entorno. Éstos constituirían, si atendemos al patrón de asentamiento que presentan los centros mencionados y a los propios datos arqueológicos que han ofrecido muchos de ellos, la base de la economía de la mayor parte de estos grandes núcleos ibéricos murcianos. En este sentido, yacimientos como Bolbax, el Cerro del Castillo de Lorca o Las Cabezuelas de Totana, desarrollaron una economía que aprovecharía al máximo las posibilidades agropecuarias y forestales del entorno, definida además, probablemente, por la presencia de un excedente agrícola que pudo distribuirse a través de las diversas vías de intercambio y rutas naturales en las que quedarían insertos muchos de estos destacados asentamientos (Santos, 1994: 43-47; Lillo, 1981: 71 y 1985: 277-278; García e Iniesta, 1984: 71 y 74-75; Grau, 2000: 39-40; Chapa y Mayoral, 1998: 65-67).
Volviendo al núcleo de Los Villaricos, y si atendemos de forma más concreta al área de captación inmediata de este centro, es decir, a aquella que quedaría englobada en un radio teórico de 2 kilómetros, vemos sin embargo que sería mucho más reducida. No alcanza las 300 hectáreas de extensión, hecho que necesariamente debemos poner en conexión con las dificultades de acceso señaladas para este yacimiento, que condicionan ampliamente la movilidad en aquel sector más próximo al mismo, donde las pendientes son más acusadas. Así, es realmente a partir de la isocrona de 30 minutos cuando la pendiente del terreno comienza a ser más fácil de salvar, siendo posible de este modo acceder a un área mucho más amplia en un tiempo más reducido.

Este cambio entre ambos intervalos apunta, claramente, a la necesidad de un desplazamiento mínimo de media hora por parte de los habitantes de este asentamiento para acceder a aquellas tierras más aptas para las actividades agropecuarias, y en las que podrían desarrollarse más ampliamente las labores agrarias por parte de la población residente en dicho centro. Estos territorios, además, se localizan en su mayor parte al oeste y suroeste del oppidum, áreas a las que, como hemos indicado, el acceso desde el asentamiento debió ser mucho más fácil. Además, tal y como ya senaló Marín de Espinosa en función de los datos de superficie observados, es en dicho sector donde pudo localizarse el acceso al recinto del hábitat (Melgares, 1974: 45-48; Marín de Espinosa, 1856 (reed. 1975): 12-13).

Más dificultades ofrece el acceso a aquel sector situado al otro lado del curso del Quípar. Las fuertes pendientes que enmarcan el cauce del río limitan la movilidad, requiriéndose así mayores costes de desplazamiento por parte de los habitantes de Los Villaricos para acceder a dicho área. Resulta interesante, en este sentido, advertir que la mayor parte de las tierras que quedan localizadas en ese sector oriental, en el entorno del vecino cerro de Los Villares y del Santuario del Cerro de la Ermita de La Encarnación, son fundamentalmente de carácter forestal. Su aprovechamiento en este caso, posiblemente para el desarrollo de actividades de tipo cinegético así como relacionadas con la explotación ganadera o forestal, pudo así otorgar a éstas un carácter secundario frente al interés que despertarían aquellas zonas de más fácil acceso, en las que se 
concentran los suelos más aptos para las labores agrícolas (Alías Pérez, 1991)(figura 5).

En este sector oriental el área de captación de Los Villaricos se extiende hasta alcanzar prácticamente el valle del Argos, en un sector además prácticamente llano y rico en recursos hídricos gracias a los numerosos manantiales presentes en toda esta zona comarcal. Sus características edafológicas lo convierten en uno de los más aptos para el desarrollo de las actividades agrarias, tal y como refleja el aprovechamiento tradicional de estas tierras y la amplia cantidad de infraestructuras destinadas a la irrigación que ocupan actualmente toda esta zona del Noroeste murciano (Alías Pérez, 1991: 3033 y 72-73). A todo ello debemos además sumar la ya citada ausencia de núcleos documentados en este sector durante el periodo ibérico, hecho que, si bien no nos permite descartar definitivamente la posible presencia de algún centro de carácter secundario en las inmediaciones del oppidum, nos lleva a pensar en una explotación desarrollada por los habitantes de dicho centro.

En general, la amplia fertilidad de estos territorios, unida al fácil acceso que los habitantes de Los Villaricos debieron tener a los mismos, nos permite plantear una economía que no debió limitarse exclusivamente al autoabastecimiento de este centro. Como hemos señalado, cabe pensar en un cierto excedente con el que, quizás, se pueden poner en conexión algunos de los hallazgos que ha ofrecido la propia necrópolis del yacimiento, como las propias importaciones áticas documentadas en ésta (García Cano, 1992: 327). Del mismo modo, la ya mencionada localización estratégica de este centro, en una de las principales rutas de comunicación del Sureste durante el Ibérico Pleno (Quesada Sanz, 1992: 66; Quesada y Martínez, 1995: 249; Brotóns Yagüe, 1995), debió significar también un impulso para el desarrollo de dichas actividades y de los intercambios, posiblemente hasta la puesta en marcha de la via Augusta.

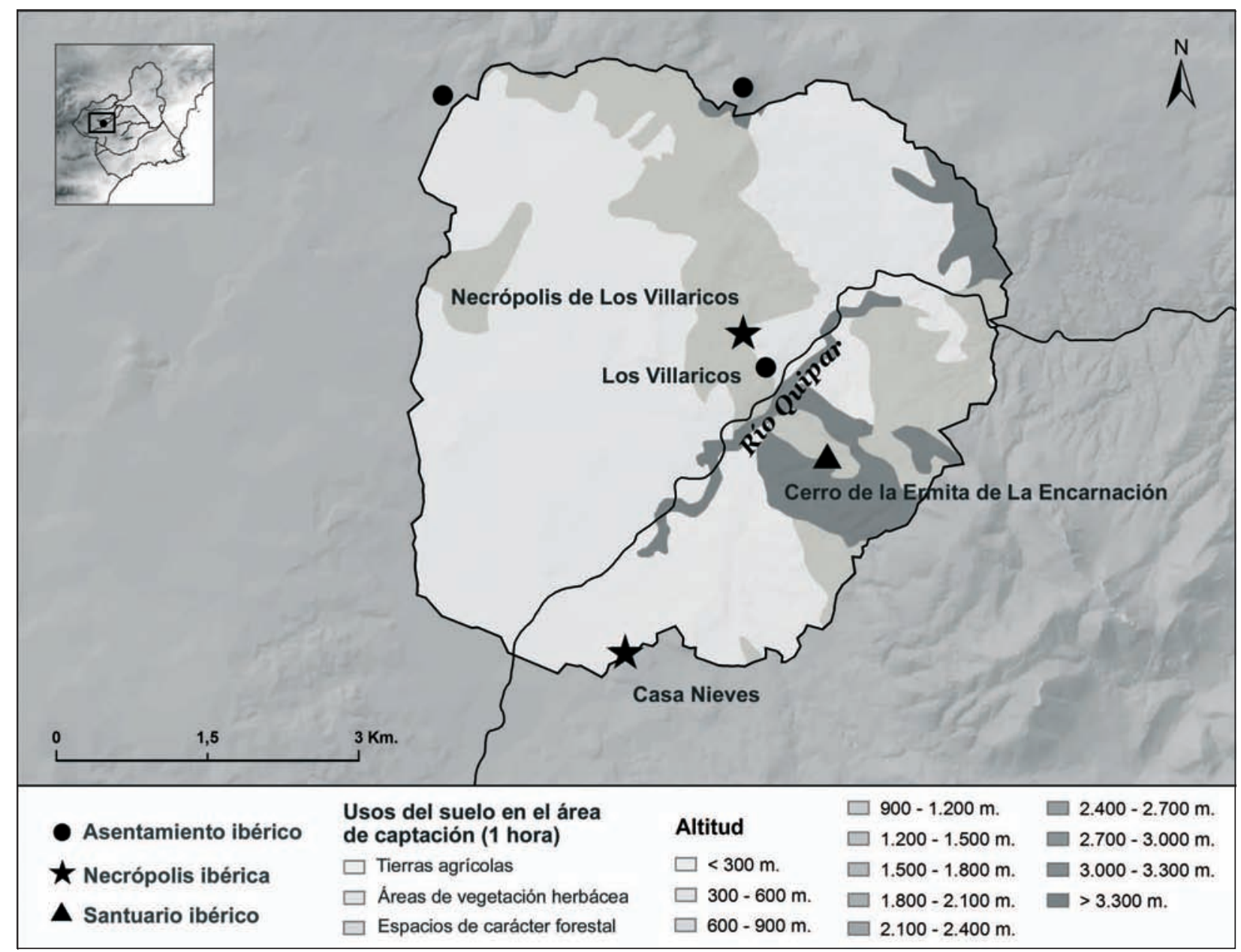

Figura 5. Área de captación económica de Los Villaricos y usos tradicionales del suelo en los distintos territorios englobados dentro de la misma. 
Los criterios económicos son así, junto a los estratégicos y defensivos, claves para comprender la decisión locacional de este oppidum y, en definitiva, su carácter y el papel que desempeñó en el conjunto del paisaje ibérico comarcal durante los siglos IV-III a.C. En dichas centurias este centro se situó a la cabeza de todo el territorio, convirtiéndose en núcleo articulador del mismo y del poblamiento que se desarrolla a lo largo de los valles del Quípar y del Argos.

\section{EL OPPIDUM DE LOS VILLARICOS Y SU PAPEL EN EL MARCO DEL PAISAJE IBÉRICO DEL NOROESTE MURCIANO.}

El asentamiento localizado en el cerro de Los Villaricos parece configurarse, si atendemos a los distintos rasgos señalados como definidores de su patrón de asentamiento, como el núcleo principal de toda este área interior murciana, frente a un poblamiento secundario de carácter disperso que veremos distribuido en las proximidades de los valles del Argos y el Quípar desde el siglo IV a.C.

Junto a su emplazamiento estratégico y el amplio acceso a las ricas tierras agrícolas de su entorno (Alías Pérez, 1991: 30-33, 43, 46, 67-69 y 72-74; Prados, Molina y Álvarez, 1991: 278279; Madoz, 1845-1850 (reed. 1989): 66; Melgares, 1974: 25-27; Fábrega, 2004: 45), así como a los ejes viarios que discurrirían por sus proximidades favoreciendo el desarrollo de las actividades de intercambio, cabe tener presentes también otros aspectos. Entre ellos su destacada posición en el paisaje comarcal y en el conjunto del poblamiento ibérico de estas tierras murcianas, que confirmarían asimismo el destacado papel de este asentamiento, al que apunta el patrón de asentamiento señalado. Tampoco podemos olvidar su amplia extensión y su continuidad cronológica, posiblemente en relación con su carácter de núcleo articulador de estos territorios, favorecida por el apoyo que las clases dirigentes de este centro debieron ofrecer desde el primer momento a Roma. Asimismo, hay que recordar su protagonismo como núcleo clave para comprender la integración en la órbita romana de estas tierras y el hecho de que no se localice, durante el Ibérico Pleno, ningún otro asentamiento en sus proximidades. Como única excepción, y ya en época tardía, encontramos la necrópolis de Casa Nieves vinculada probablemente a un pequeño asentamiento rural aun por localizar (San Nicolás, 1987: 181-182; García Cano, 1992: 327). Como apuntábamos, ese aparente vacío poblacional en las inmediaciones del oppidum así interpretarse como un reflejo de la entidad alcanzada por este centro, que sería el responsable de la explotación directa de las ricas tierras inmediatas (Burillo, 1982: 40; Hodder y Orton, 1999: 72-73) (figura 6).

En general, desde una perspectiva más amplia que la del mero emplazamiento del oppidum, y tras los diversos aspectos señalados, podemos apuntar a una serie de rasgos esenciales que definirían la posición de este centro en el territorio. No sólo lo diferencian del resto de establecimientos localizados en la comarca, sino que, de algún modo, completan la imagen del mismo ofrecida, como hemos señalado, por su propio patrón de asentamiento. Entre ellos, aquellos que quizás mejor reflejarían dicho papel en el ámbito comarcal son precisamente los relativos a su control visual y a su evolución partir del siglo II a.C. con la presencia romana, marcada por el desarrollo que experimentará el santuario vinculado a él. En clara relación con ellos, además, no podemos olvidar su posible papel sociopolítico y como residencia del grupo indígena que se hallaría a la cabeza de toda este área y del resto del poblamiento que vemos en ambos valles desde el siglo IV a.C.

Por lo que respecta al amplio control del territorio comarcal que pudo ser ejercido desde este núcleo constituye, como hemos apuntado, uno de esos criterios que a nivel comarcal nos permiten situarlo a la cabeza del resto de centros ibéricos localizados en toda este área del Noroeste murciano. Su cuenca visual, extendida sobre el valle del Quípar y el sector de altiplanos más septentrional de la comarca y constituye uno de los rasgos que mejor definen su patrón de asentamiento. Es un factor clave para valorar el posible papel de este oppidum como centro organizador del poblamiento y de la explotación en este área del interior regional (Recio, 2002: 73; Ciampoltrini y Andreotti, 2002: 56). Recordemos, en este sentido, que son precisamente aquellos centros que ejercen un papel destacado en el territorio los que aparecen generalmente mejor comunicados visualmente, presentando cuencas visuales amplias, en ocasiones centradas en puntos clave de paso (Grau Mira, 2004: 68-73; Ruestes i Bitrià, 2006: 230-243; Castro y Gutiérrez, 2001: 155-156; Bonilla Martos, 2004: 119-133; Marín Rubio, 2004: 95- 


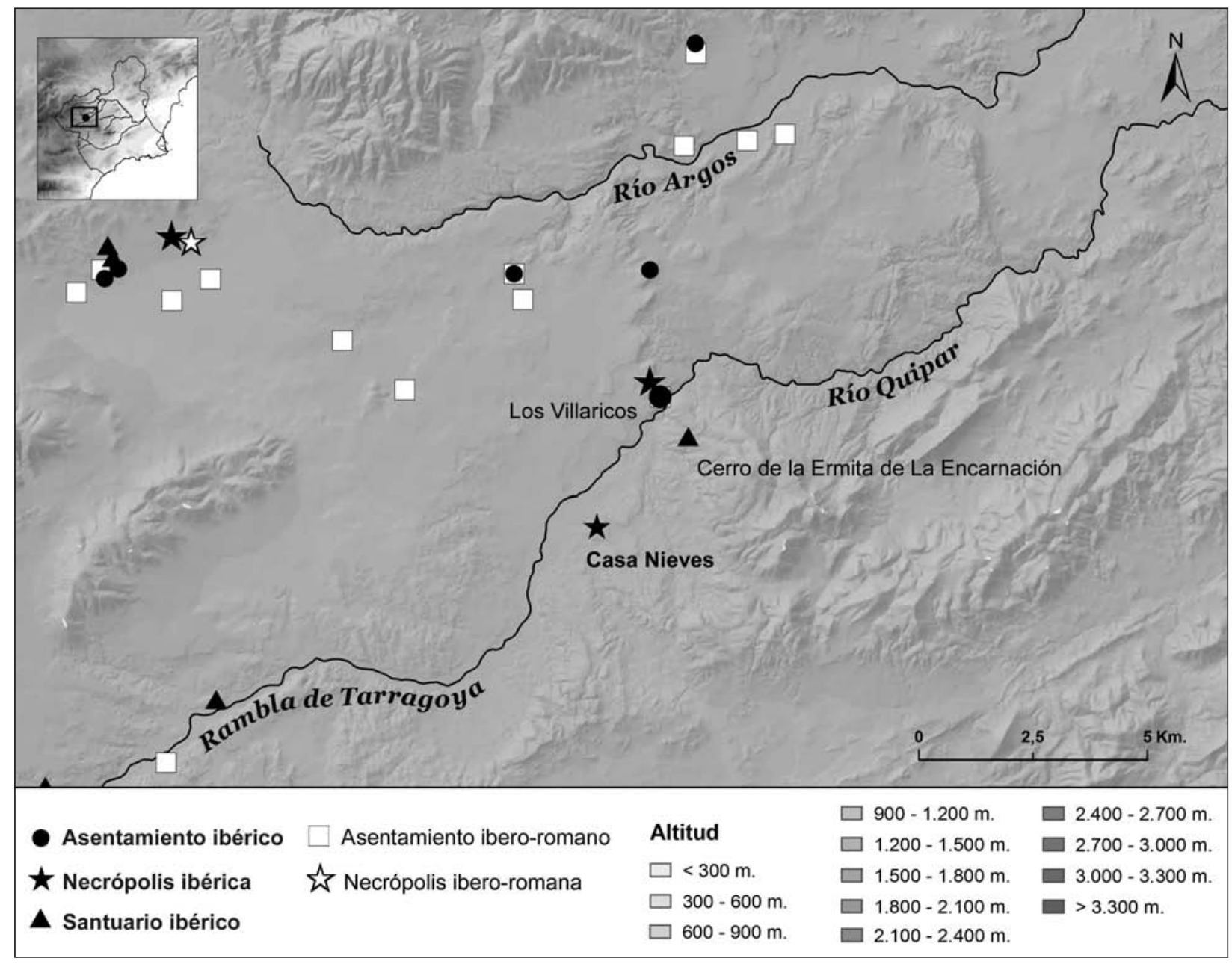

Figura 6. Asentamientos ibéricos e ibero-romanos en el entorno del oppidum de Los Villaricos.

96). Al mismo tiempo son éstos los que generalmente muestran un claro interés por 'ser vistos' en el paisaje, cuestión en la que sus murallas serán el mejor aliado, sin olvidar, claro está, el carácter defensivo de las mismas (Moret, 2003: 177-180; Grau, 2004: 68-72; Criado, 1999: 34; Mañana, Blanco y Ayán, 2002: 38-39).

Tampoco podemos dejar de lado el interés de este oppidum por lograr un dominio visual directo de aquellas tierras más aptas para el desarrollo de las actividades agrícolas, cuyos recursos hídricos y suelos ofrecían las mejores condiciones en este sentido (Alías, 1991: 30-32 y 46; Melgares, 1974: 25-27; Prados, Molina y Álvarez, 1991: 278-279; Madoz, 1845-1850 (reed. 1989): 66). Lo mismo ocurre con aquel sector por donde discurrirían las principales vías de comunicación e intercambio que, atravesando el Noroeste murciano, se dirigían hacia la actual Andalucía, tal y como demuestran las importaciones documentadas en las necrópolis comarca- les de La Poza y el Villar de Archivel (Brotóns Yagüe, 2009).

Otra cuestión de interés es la presencia de un posible punto de vigilancia en el vecino Cerro de la Cueva IV, con el que el oppidum mantiene una clara conexión visual. Este establecimiento completaría el control de Los Villaricos, dominando visualmente el sector más septentrional del valle del Argos y la ruta de enlace con el área de Cehegín que escapan al control visual directo del oppidum (figura 7). Dicha conexión, documentada también en otras áreas peninsulares (Grau Mira, 2004: 68-73; Marín Rubio, 2004: 95-96; Ruestes i Bitrià, 2006: 230-243; Castro y Gutiérrez, 2001: 155-156), reflejaría asimismo el interés de Los Villaricos por lograr el control territorial de esas áreas, y vendría a confirmar de nuevo a este yacimiento como núcleo destacado del territorio.

El modelo de control y articulación territorial que refleja Los Villaricos se centra así en el área 
del Estrecho de las Cuevas, el sector de altiplanicies septentrionales de la comarca analizada y el valle del Quípar, sin olvidar aquel área más septentrional, controlada a través de esa conexión visual con el Cerro de la Cueva IV.

Podríamos señalar así que el modelo organizativo que parece advertirse en la comarca se articula, de este modo, en torno al eje fluvial del Quípar, junto al que se dispondrá la mayor parte de los asentamientos de este periodo siguiendo un esquema similar al documentado en otras áreas ibéricas peninsulares (Santos, 1992: 34-36; Ruiz y Molinos, 1993: 122-124 y 140-141; Ruiz y Sanmartí, 2003: 46-47; Ruiz et al., 2001: 1415; Marín Rubio, 2004: 92-93; Castro y Gutiérrez, 2001: 147-148; Blasco, 2001: 206210) y en otros ámbitos mediterráneos en época prerromana (Cultraro, 2005: 594; D'Ercole, Di Gennaro y Guidi, 2002: 117; De Lucia Brolli, 1991: 5-20). En este último, baste recordar la estrategia que define el emplazamiento de deter- minados núcleos, como el de Monte Bibele, en el valle del Idice. Su patrón de asentamiento reflejaría unos intereses muy similares a los de Los Villaricos, controlando un importante eje de comunicaciones así como los ricos territorios de la vega media de dicho curso fluvial en torno al que se organiza el resto del poblamiento, definido por establecimientos rurales de carácter secundario (Vitali, 1989: 528-535). De este modo el oppidum, como harán muchos de esos núcleos principales, pudo funcionar también gracias a su posición destacada en el territorio y privilegiada desde el punto de vista defensivo, como garante de la seguridad de muchos de esos centros secundarios, todos ellos sin aparentes defensas artificiales o naturales convirtiéndose en punto de cohesión de ese poblamiento rural.

El interés de la mayor parte de estos centros principales, entre ellos el propio oppidum de Los Villaricos, no se limitará sin embargo únicamente a lograr el control de esos territorios sino que,

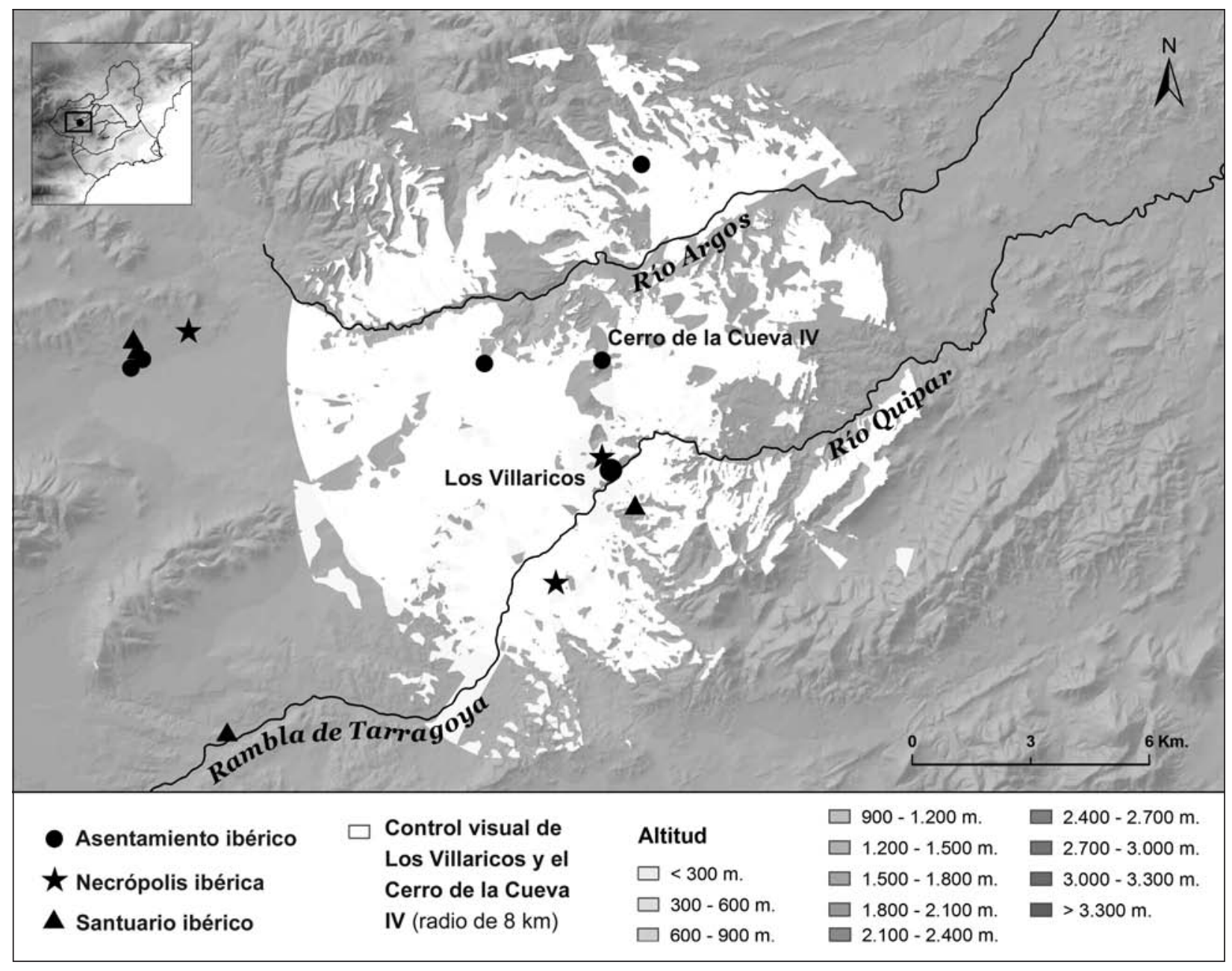

Figura 7. Dominio visual del oppidum de Los Villaricos y del núcleo instalado en el Cerro de la Cueva IV. 
además, buscará también 'hacerse presentes en ellos'. Desde este punto de vista no sólo esa cuenca visual se convierte en un aspecto fundamental, sino también la propia visibilización en el paisaje, apuntando de nuevo en el caso de Los Villaricos, a su destacado papel en el marco del mundo ibérico de estos territorios interiores (Lillo, 1981). En este sentido, y como se ha señalado para otras áreas ibéricas, las murallas de estos centros funcionarán como un 'enjeu d'image', una auténtica puesta en escena que representa su poder al frente de estos territorios (Moret, 1998: 83-92 y 2003: 177-180).

Desde esta perspectiva, el análisis de las condiciones de visualización del oppidum, tanto de su cuenca o capacidad visual, como de su visibilización en el territorio, y el de las conexiones visuales que pudo establecer con otros centros ibéricos de su entorno, no sólo nos ayuda a comprender mejor su patrón de asentamiento, sino el carácter de este yacimiento y el modelo de defensa y control de estos territorios durante el Ibérico Pleno (Bonilla, 2004: 119-133; Criado, 1999: 18).

Ese doble interés por el control de tierras y rutas de comunicación, así como muchos de los criterios que caracterizan la decisión locacional del oppidum ponen de manifiesto una situación similar a la apuntada para otros importantes centros ibéricos del sur y Sureste peninsular, como los localizados en Tutugi (Granada) o el Cerro del Castillo de Lezuza (Aguayo y Salvatierra, 1987: 230-236; Sanz Gamo, 1999: 281-284). Dichos rasgos y los paralelos que ofrece en conexión con esos otros centros pueden resultar de enorme interés a la hora de aproximarnos a la organización del poblamiento en este área murciana desde época ibérica y hasta la definitiva instalación romana en la zona. Resulta interesante, en este sentido, tener presente el hecho de que la mayor parte de los oppida ibéricos regionales ofrece también amplias cuencas visuales. En el caso de aquellos localizados en el valle del Segura lograron un importante control sobre amplios tramos de este curso fluvial, que aparece de este modo organizado en distintas unidades territoriales, a la cabeza de las cuales se situan distintos oppida, que funcionarían como articuladores de una misma ruta de intercambios (Grau Mira, 2000: 41-42).

El esquema que ofrece el poblamiento en el valle del Quípar apunta así a un modelo similar al de esos otros ámbitos meridionales peninsulares. En él Los Villaricos se situa a la cabeza de un amplio territorio, dominando la vía de comunicación natural que discurre junto a él y todo un conjunto de establecimientos de segundo orden disperso en toda este área.

Como indicábamos, otro de los aspectos que al margen de su propio patrón de asentamiento refleja también la importancia que este centro alcanza en época ibérica e ibero-romana, es la presencia del ya citado santuario del Cerro de la Ermita de La Encarnación y el desarrollo que este experimenta con la llegada de Roma.

Este tipo de espacios, generalmente vinculados a los grandes centros ibéricos localizados en el Sureste, apunta, junto a las cuestiones señaladas, al papel destacado de Los Villaricos frente al resto de los centros localizados en el Noroeste murciano en estos momentos. Sólo en este contexto, y enmarcado en el reconocimiento de este santuario y del oppidum por parte de la comunidad ibérica de estos territorios, es posible comprender la transformación edilicia que se observa en el Cerro de la Ermita de La Encarnación y el destacado papel que debió jugar este área de culto, a partir del siglo II a.C., en el proceso de romanización de toda esta zona regional murciana.

Como hemos indicado, no podemos olvidar, en conexión con este último aspecto y con el propio papel de Los Villaricos en el conjunto del valle, aquellas cuestiones de índole sociopolítica. Una de ellas es el propio hecho de que este centro sea el único que presente rasgos que permitan identificarlo como el núcleo donde residiría el grupo dirigente que se hallaría a la cabeza de todo este territorio.

$\mathrm{Si}$ atendemos a los aspectos señalados y a los criterios que definen su patrón de asentamiento, el oppidum de Los Villaricos funcionará como núcleo principal de este área. Hemos indicado cómo su posición estratégica le permitiría desarrollar funciones organizativas y de control territorial y económico. Éstas favorecerán a su vez su consolidación como centro principal de todo este territorio, permitiéndole alcanzar un importante desarrollo que implicó también una mayor complejidad en las relaciones sociales (Ongil Valentín, 1986: 165-166).

Como apuntábamos al inicio del trabajo, los escasos datos materiales de los que disponemos para este centro nos impiden advertir de forma 
precisa, a través del registro arqueológico, la presencia de una élite indígena destacada. A pesar de ello, algunos de los aspectos apuntados en relación con su patrón de asentamiento, como la entidad alcanzada el citado interés por presentarse como núcleo principal y punto de control de toda el área, y su aparente integración en los circuitos de intercambio que atravesarían estas tierras, y a través de los que esa élite obtendrá elementos de prestigio como los recuperados en la necrópolis de este centro, apuntan en esta dirección (García Cano 1992; Ongil Valentín, 1986: 165-166).

Al margen de este área funeraria, también el vecino santuario ibérico del Cerro de la Ermita de La Encarnación se debe interpretar, como se ha señalado para determinados ámbitos del mundo ibérico del sur peninsular, como un reflejo de la autoafirmación de ese grupo dirigente frente al resto de la comunidad. Éste conformará su poder a través de espacios de culto claramente vinculados a estos núcleos principales y que adquirirán una importancia destacada dentro del conjunto del territorio (Moneo, 2003: 320-329; Moneo y Almagro, 1998: 93-98; Ruiz, 1999a: 79-91 y 1999b: 104-105; Santos Velasco, 1994: 47-50; Ruiz y Molinos, 1993: 248-249 y 1999: 229-237). En este sentido, la entidad que refleja el santuario frente al resto de aquellos localizados en el Noroeste murciano apunta también en esa misma línea.

Ya para época ibero-romana quizás sean precisamente las amplias transformaciones que experimenta este área de culto el mejor reflejo en este sentido. La construcción de dos nuevos templos siguiendo modelos arquitectónicos y decorativos propios del mundo itálico confirma de forma indirecta la importancia del núcleo ibérico vinculado al santuario y la relación "amistosa", por así decirlo, que se establecerá entre romanos e indígenas.

En esta misma línea puede interpretarse la continuidad del oppidum de Los Villaricos durante los siglos II-I a.C. Ésta, como se ha señalado también para otros ámbitos ibéricos y del Mediterráneo, sólo resulta comprensible en conexión con el interés de Roma por mantener el status quo durante esos primeros momentos de su presencia en la Península, y con el apoyo que pudo recibir de los dirigentes locales de muchos de esos oppida. Estos, si bien perderán la amplia autonomía de la que disfrutaban hasta el momento, lograrán en cambio mantener aun sus privilegios y su control sobre estos territorios (Ramallo, Noguera y Brotóns, 1998: 11-69).

Desde esta perspectiva se confirma la capacidad de control de Los Villaricos tanto desde el punto de vista de la explotación de estos territorios, como también del eje de comunicación que, siguiendo los valles comarcales accederá al área granadina y de los núcleos rurales dispersos en todo este sector regional.

El oppidum de Los Villaricos, ocupando una posición clave en el paisaje comarcal del Noroeste murciano, extendió así su influencia y control a toda este área. Este control pudo estar además completado, si atendemos panorama documentado para determinados espacios de culto en otras áreas peninsulares y del Mediterráneo, por el santuario del Cerro de la Ermita de la Encarnación (Ongil Valentín, 1986: 165-166; Moneo, 2003: 137, 233 у 265-266; Cultraro, 2005: 594; De Lucia Brolli, 1991: 23).

\section{CONCLUSIONES Y PERSPECTIVAS DE TRABAJO.}

Como hemos podido advertir, y a pesar del escaso conocimiento que desde el punto de vista propiamente arqueológico se tiene hoy por hoy del núcleo ibérico emplazado en Los Villaricos, el análisis de su estrategia locacional así como de aquellos rasgos que definen su situación en el marco del paisaje ibérico comarcal del Noroeste murciano, nos permiten aproximarnos por primera vez a este centro desde un nuevo punto de vista. El estudio de los criterios estratégicos que caracterizan su emplazamiento, ya no sólo a nivel del propio yacimiento, sino también a escala comarcal, en el conjunto del territorio y del poblamiento ibérico localizado en todo este sector regional, ofrece así interesantes aspectos sobre el citado oppidum, esbozando algunos de los rasgos que definen el modelo de articulación y control del territorio en el Noroeste murciano y, en concreto, en el valle medio - alto del Quípar.

La escasez de trabajos arqueológicos de excavación en este núcleo ha llevado a la historiografía murciana a dejarlo en un segundo plano frente a otros oppida regionales, cuyas necrópolis son ampliamente conocidas. Frente a ello las nuevas perspectivas de estudio que ofrecen el análisis del paisaje y los Sistemas de Información Geográfica, sirven como punto de 
partida para abordar un estudio del poblamiento ibérico en este ámbito regional, y logrando una primera aproximación a uno de los núcleos más destacados del Sureste peninsular. Como hemos señalado, su claro carácter estratégico, su extensión, su emplazamiento sus defensas naturales y artificiales, el área de culto vinculada a él, sus posibilidades económicas y el control que ejercerá sobre toda este área comarcal y sobre el resto de los núcleos documentados en ella, hacen de él el yacimiento clave para comprender el desarrollo del mundo ibérico en toda este área, y apuntan claramente a su importante papel en el marco del territorio comarcal.

En este sentido, la actuación romana en este sector murciano, marcada por el desarrollo que experimenta el santuario del Cerro de la Ermita de La Encarnación, demuestra que Roma supo comprender desde el primer momento, el papel de este centro en el territorio. Sólo así se entiende el interés romano tanto por asegurar la continuidad del oppidum, siendo el único núcleo ibérico de todo el valle que se mantendrá hasta época imperial, como por consolidar simbólicamente este yacimiento a través de la transformación edilicia que desarrollará en su santuario (Ramallo, 1991: 63 y 1993: 133; Ramallo, Noguera y Brotóns, 1998: 11-69; Moneo, 2003: 157 y 341-344).

\section{BIBLIOGRAFÍA}

ADROHER AUROUX, A. M. y LÓPEZ MARCOS, A. (Dir.) (2004): El territorio de las altiplanicies granadinas entre la Prehistoria y la Edad Media: arqueología en Puebla de Don Fadrique (1995-2002). Sevilla.

AGUAYO DE HORNOS, P. y SALVATIERRA CUENCA, V. (1987): "El poblamiento ibérico en las altiplanicies granadinas". Iberos. Actas de las primeras Jornadas sobre el Mundo Ibérico (Jaén, 1985), 229-238. Jaén.

ALÍAS PÉREZ, L. J. (Dir.) (1991): Proyecto LUCDEME. Mapa de suelos. Escala 1:100.000. Caravaca - 910. Madrid.

BLASCO BOSQUED, C. (2001): "El poblamiento en las cuencas de los ríos Duero y Tajo durante la Edad del Hierro". BERROCAL-RANGEL, L. y GARDES, P. (Coord.): Entre celtas e íberos. Las poblaciones protohistóricas de las Galias e Hispania, 201-212. Madrid.
BONILLA MARTOS, A. L. (2004): "Poblamiento y territorio en el Suroeste de la provincia de Jaén en época ibérica". Arqueología y Territorio 1, 119-133.

BROTÓNS YAGÜE, F. (1995): "El poblamiento romano en el valle alto del Quípar (Rambla de Tarragoya), Caravaca de la Cruz (Murcia)". NOGUERA CELDRÁN, J. M. (Coord.): Poblamiento rural romano en el Sureste de Hispania. (Actas de las Jornadas celebradas en Jumilla el 8 al 11 de noviembre de 1993), 247274. Murcia.

BROTÓNS YAGÜE, F. (2009): "La necrópolis tumular ibérica de "El Villar de Archivel" (Caravaca de la Cruz-Murcia)". Actas del I Congreso Internacional de Arqueología Ibérica Bastetana (Baza, 7 - 10 mayo de 2008). Baza.

BROTÓNS YAGÜE, F. y MURCIA MUÑOZ, A. J. (2008): "Los castella tardorrepublicanos de la cuenca alta de los ríos Argos y Quípar (Caravaca, Murcia). Aproximación arqueológica e histórica”. Del imperium de César a la avctoritas de Augusto. Anejos del Archivo Español de Arqueología XLVII, 49-66.

BURILLO MOZOTA, F. (1982): "Modelos sobre la utilización del medio geográfico en época ibérica en el valle medio del Ebro". Memorias de Historia Antigua III-1979, 31-45.

CASTRO LÓPEZ, M. y GUTIERREZ SOLER, L. (2001): "Conquest and Romanization of the upper Guadalquivir valley". Italy and the West. Comparative issues in Romanization, 145-160. Oxford.

CHAPA BRUNET, T. y MAYORAL HERRERA, V. (1998): "Explotación económica y fronteras políticas: diferencias entre el modelo ibérico y el romano en el límite entre la Alta Andalucía y el Sureste". Archivo Español de Arqueología 71, 63-77.

CIAMPOLTRINI, G. y ANDREOTTI, A. (2002): "Dalla preistoria all'età romana: archeologia del territorio". CECCARELLI LEMUT, M. L. y GARZELLA, G. (a cura di): Un territorio all'incrocio di vie di terra e d'acqua: Bientina dall'Antichità al Medioevo, 55-60. Pisa.

CRIADO BOADO, F. (1999): Del Terreno al Espacio: Planteamientos y perspectivas para la Arqueología del Paisaje, CAPA 6. Santiago de Compostela. 
CULTRARO, M. (2005): "Dimore sacre e luoghi del tempo: Appunti per uno studio della percezione dello spazio sacro nella Sicilia dell'Antica Età del Bronzo". Papers in Italian Archaeology VI. Communities and settlements from the Neolithic to the Early Medieval Period. Proceedings of the 6 Conference of Italian Archaeology held at the University of Groningen, Groningen Institute of Archaeology, The Netherlands, April 15-17, 2003. Volume I, BAR International Series 1452 (II), 588-595.

D'ERCOLE, V., DI GENNARO, F. y GUIDI, A. (2002): "Valore e limiti dei dati archeologici nella definizione delle linee di sviluppo delle comunità protostoriche dell'Italia centrale". MOLINOS, M. y ZIFFERERO, A. (a cura di): Primi popoli d'Europa. Proponte e riflessioni sulle origini della civiltà nell'Europa mediterranea, 111-126. Florencia.

DE LUCIA BROLLI, M. A. (1991): L'agro Falisco. Roma.

FÁBREGA ÁlVAREZ, P. (2004): Poblamiento y territorio de la Cultura Castreña en la comarca de Ortegal, CAPA 19. Santiago de Compostela.

GARCÍA CANO, J. M. (1992): "Las necrópolis ibéricas en Murcia”. BLÁNQUEZ PÉREZ, J. y ANTONA, V. (Coord.): Congreso de Arqueología Ibérica: Las necrópolis, 313-347. Madrid.

GARCÍA CANO, J. M. e INIESTA SANMARTÍN, A. (1984): "Hipótesis sobre el desarrollo histórico de la cultura ibérica en el noroeste de la Región de Murcia”. Anales de la Universidad de Murcia, Filosofía y Letras XLII, 3-4, 71-76.

GRAU MIRA, I. (2000): “Continuidad y cambio en la trama urbana del Conventus Carthaginensis durante el proceso de romanización". Anales de Prehistoria y Arqueología. Universidad de Murcia 16, 33-51.

GRAU MIRA, I. (2002): La organización del territorio en el área central de la Contestania Ibérica. Alicante.

GRAU MIRA, I. (2004): "La construcción del paisaje ibérico: aproximación SIG al territorio protohistórico de la Marina Alta". Saguntum (P.L.A.V.) 36, 61-75.

HODDER, I. y ORTON, C. (1999): Análisis espacial en arqueología. Barcelona.
LILLO CARPIO, P. A. (1981): El poblamiento ibérico en Murcia. Murcia.

LILLO CARPIO, P. A. (1985): "La cultura ibérica en tierras murcianas". Arqueología del País Valenciano: panorama y perspectivas. Anejo a Lucentum, 273-280. Alicante.

LILLO CARPIO, P. A. (1993): El poblado ibérico de Los Molinicos. Moratalla (Murcia). Murcia.

MACCHI JÁNICA, G. (2001): "Sulla misurazione delle forme d'occupazione sociale dello spazio medievale". Archeologia Medievale XXVIII, 7-21.

MADOZ, P. 1850 (reed. 1989): Diccionario geográfico-estadístico-histórico de España y sus posesiones de ultramar. Región de Murcia. Murcia.

MAÑANA BORRAZÁS, P., BLANCO ROTEA, R. y AYÁN VILA, X. M. (2002): Arqueotectura 1: bases teórico-metodológicas para una arqueología de la arquitectura, TAPA 25. A Coruña.

MARÍN DE ESPINOSA, A. (1856 (reed. 1975)): Memorias para la historia de la ciudad de Caravaca. Barcelona.

MARÍN RUBIO, E. (2004): "Una hipótesis sobre la organización del territorio en época ibérica en la cuenca del río Algarra". Saguntum (P.L.A.V.) 36, 77-96.

MELGARES GUERRERO, A. (1974): La carta arqueológica del término municipal de Caravaca de la Cruz. Universidad de Murcia. Tesis de Licenciatura inédita.

MONEO, T. (2003): Religio Iberica. Santuarios, ritos y divinidades (siglos VII-I a.C.), Biblioteca Archaeologica Hispana n. 20. Madrid.

MONEO, T. y ALMAGRO-GORBEA, M. (1998): "Santuarios y elites ibéricas". ARANEGUI GASCÓ, C. (Ed.): Actas del Congreso Internacional. Los Iberos. Príncipes de occidente, 93-98. Barcelona.

MORET, P. (2003): "Fortifications ibériques tardives et défense du territoire en Hispaine Citérieure". MORILlO, A. et al. (Coord.): Defensa y territorio en Hispania de los Escipiones a Augusto. Actas del coloquio celebrado en la Casa de Velázquez (19-20 marzo 2001), 159-183. Universidad de León / Casa de Velázquez.

ONGIL VALENTÍN, M. I. (1986): “Centros de poder y redistribución en época prerromana". Norba $\mathrm{n}^{\circ}$ 7, 163-166. 
PRADOS TORREIRA, L. (1994): “Los santuarios ibéricos. Apuntes para el desarrollo de una Arqueología del Culto". Trabajos de Prehistoria 51, 1, 127-142.

PRADOS TORREIRA, L., MOLINA LÓPEZ, E. y ALVAREZ MORALES, C. (1991): "Las transformaciones del paisaje agrario en época histórica: estudio de las fuentes documentales". LÓPEZ GARCÍA, P. (Ed.): El cambio cultural del IV al II milenios a.C. en la comarca Noroeste de Murcia, vol. 1, 275-313. Madrid.

QUESADA SANZ, F. (1992): "El casco de Almaciles (Granada) y la cuestión de los cascos de tipo 'Montefortino' en la Península Ibérica”. Verdolay 4, 65-73.

QUESADA SANZ, F. y MARTÍNEZ, A. (1995): “Un lote de armas procedente del yacimiento de Carranza (Huéscar de Granada) y la cuestión de las vías de comunicación entre Granada y Murcia”. Verdolay 7, 239-250.

RAMALLO ASENSIO, S. F. (1991): “Un santuario de época tardorrepublicana en la Encarnación, Caravaca, Murcia". Templos romanos en Hispania. Cuadernos de Arquitectura romana 1, 39-65. Murcia.

RAMALLO ASENSIO, S. F. (1993): "La monumentalización de los santuarios ibéricos en época tardo-republicana". Ostraka (Rivista di Antichità) II, 1, 117-144.

RAMALLO ASENSIO, S. F. y ROS SALA, M. M. (1993): Itinerarios arqueológicos de la Región de Murcia. Murcia.

RAMALLO ASENSIO, S. F., NOGUERA CELDRÁN, J. M. y BROTÓNS YAGÜE, F. (1998): "El Cerro de los Santos y la monumentalización de los santuarios ibéricos tardíos". Revista de Estudios Ibéricos 3, 11-69.

RECIO RUIZ, A. (2002): "Formaciones sociales ibéricas en Málaga". CRUZ ANDREOTTI, G., et al. (Coord.): Mainake. Colonizadores $e$ Indígenas en la Península Ibérica XXIV, 35-81. Málaga.

RIVERA NUÑEZ, D., OBON DE CASTRO, C. y ASENCIO MARTÍNEZ, A. (1988): “Arqueobotánica y paleoetnobotánica en el Sureste de España. Datos preliminares". Trabajos de Prehistoria 45, 317-334.
RUESTES I BITRIÀ, C. (2006): “El poblamiento ibérico y romano en la Layetania litoral (del río Besòs a la Riera de Teià). Aplicación arqueológica de un SIG”. GRAU MIRA, I. (Ed.): La aplicación de los SIG en la arqueología del paisaje, 227-246. Alicante.

RUIZ RODRÍGUEZ, A. (1987): “Ciudad y territorio en el poblamiento ibérico del Alto Guadalquivir". Los asentamientos ibéricos ante la romanización (27-28 febrero 1986), 9-21. Madrid.

RUIZ RODRÍGUEZ, A. (1999a): "Los Iberos del Alto Valle del Guadalquivir". SALVATIERRA, V. y RÍSQUEZ, C. (Ed.): De las sociedades agrícolas a la Hispania romana. Jornadas Históricas del Alto Guadalquivir, 61-79. Jaén.

RUIZ RODRÍGUEZ, A. (1999b): “Origen y desarrollo de la aristocracia en época ibérica, en el alto Valle del Guadalquivir". Les Princes de la Protohistoire et l'émergence de l'état. Actes de la table ronde internationale organisée par le Centre Jean Bérard et l'École française de Rome, Naples, 27-29 octobre 1994, 97-106. Nápoles-Roma.

RUIZ RODRÍGUEZ, A., et al. (2001): "El modelo político del pago en el alto Guadalquivir (s. IVIII a.n.e.)". Territori politic $i$ territori rural durant l'edat del Ferro a la Mediterrània Occidental, Actes de la Taula Rodona celebrada a Ullastret, 11-22. Girona.

RUIZ RODRÍGUEZ, A. y MOLINOS MOLINOS, M. (1993): Los iberos. Análisis arqueológico de un proceso histórico. Barcelona.

RUIZ RODRÍGUEZ, A. y MOLINOS MOLINOS, M. (1999): "Las primeras aristocracias iberas del valle del Guadalquivir: territorios nucleares y formas sociales de clientela". Ostraka (Rivista di Antichità) 8, 221-238.

RUIZ RODRÍGUEZ, A. y SANMARTÍ, J. (2003): "Models comparats de poblament entre els ibers del nord i del sud". Territoris Antics a la Mediterrània i a la Cossetània oriental, 39-57. Barcelona.

SAN NICOLÁS DEL TORO, M. (1987): "Excavación de urgencia en la necrópolis ibérica de 'Casa Nieves' (La Encarnación, Caravaca)". Excavaciones y Prospecciones Arqueológicas, 181-182. Murcia. 
SANTOS VELASCO, J. A. (1992): “Territorio económico y político del sur de la Contestania Ibérica”. Archivo Español de Arqueología 65, 33-47.

SANTOS VELASCO, J. A. (1994): Cambios sociales y culturales en época ibérica: el caso del Sureste. Madrid.

SANZ GAMO, R. (1999): "De los oppida ibéricos a las ciudades romanas en el territorio de la provincia de Albacete". XXIV Congreso Nacional de Arqueología (Cartagena, 1997) 4, 281-284.

VITALI, D. (1983): “La valle dell'Idice tra V e II secolo a.C.". Monterenzio e la valle dell'Idice. Archeologia e storia di un territorio, 83-86. Casalecchio di Reno. 